\title{
Profil kepemilikan dan tingkat pengetahuan ibu-ibu tentang buku kia di Kabupaten Padang Pariaman
}

\author{
Masrul \\ Bagian Ilmu Gizi, Fakultas Kedokteran Universitas Andalas \\ Korespondensi: Masrul, email: masrul@med.unand.ac.id
}

\begin{abstract}
Abstrak
Angka Kematian Ibu (AKI) dan Angka Kematian Bayi (AKB) merupakan indikator yang mampu menilai derajat kesehatan masyarakat. Salah satu upaya untuk menurunkan angka kematian ibu dan anak adalah dengan memperbaiki pelayanan kesehatan terutama kesehatan Ibu dan Anak (KIA) dengan pemanfaatan penggunaan buku KIA. Tujuan: Untuk menentukan tingkat kepemilikan buku KIA dan tingkat pemahaman ibu terhadap buku KIA yang dimiliki. Metode: Data ini sebagian dari penelitian yang menggunakan kuasi eksperimental pre-post dimana pada 3 kecamatan di Kabupaten Padang Pariaman. Kecamatan yang diambil adalah kecamatan yang masalah stunting cukup tinggi, kemudian tingkat kepemilikan buku KIA yang rendah dan angka penimbangan yang rendah. Jumlah sampel yang diambil sebanyak 102 responden ibu hamil, dan ibu yang memiliki anak balita. Hasil: Lebih dari sepertiga $37,3 \%$ ibu yang memiliki tingkat pendidikan yang rendah, $81,4 \%$ ibu tidak bekerja atau menjadi ibu rumah tangga. Sebanyak $83,3 \%$ ibu yang memiliki buku KIA. Simpulan: Sebagian besar responden (>75\%) tidak tahu informasi yang ada di buku KIA. Masih ada ibu-ibu yang tidak memiliki buku KIA dan masih rendahnya informasi yang dimiliki ibu-ibu tentang buku KIA.

Kata kunci: buku KIA; pengetahuan ibu; kesehatan masyarakat
\end{abstract}

\begin{abstract}
Maternal Mortality Rate (MMR) and Infant Mortality Rate (IMR) are indicators that are able to assess the degree of public health. One effort to reduce maternal and child mortality is to improve health services, especially maternal and child health $(\mathrm{MCH})$, by using $\mathrm{MCH}$ handbook. Objective: To determine the level of ownership of the $\mathrm{MCH}$ handbook and the level of understanding of the mother of the $\mathrm{MCH}$ handbook owned. Method: This data is part of the study using quasi-experimental pre-post which in 3 sub-districts in Padang Pariaman Regency. Subdistricts taken are sub-districts where the problem of stunting is quite high, then the level of ownership of the $\mathrm{MCH}$ handbook is low and the rate of weighing is low. The number of samples taken was 102 respondents of pregnant women, and mothers who had children under five. Results: More than a third of $37.3 \%$ of mothers had low levels of education, $81.4 \%$ of mothers did not work or become housewives. About $83.3 \%$ of mothers have MCH handbook. Most respondents (>75\%) did not know the information in the $\mathrm{MCH}$ handbook. Conclusion: there are still mothers who do not have the $\mathrm{MCH}$ Handbook and the information that mothers still have about $\mathrm{MCH}$ handbook.
\end{abstract}

Keywords: MCH handbook; mother's knowledge; Public Health 


\section{PENDAHULUAN}

Sebagai komponen yang tidak terpisahkan dari masyarakat, keluarga memiliki peran signifikan dalam status kesehatan. Ibu dan anak merupakan anggota keluarga yang perlu mendapatkan prioritas dalam penyelenggaraan upaya kesehatan, karena ibu dan anak merupakan kelompok rentan terhadap keadaan keluarga dan sekitarnya secara umum. Hal ini yang menjadi alasan pentingnya upaya kesehatan ibu dan anak menjadi salah satu prioritas pembangunan kesehatan di Indonesia. Sehingga penilaian terhadap status kesehatan dan kinerja upaya kesehatan ibu dan anak penting untuk dilakukan. ${ }^{1,2}$

Angka Kematian Ibu (AKI) dan Angka Kematian Bayi (AKB) merupakan indikator yang mampu menilai derajat kesehatan masyarakat. Secara umum terjadi penurunan kematian ibu selama periode 1991-2015. Terjadi penurunan AKI di Indonesia dari 390 pada tahun 1991 menjadi 305 pada tahun 2015. Angka kematian anak dan tahun ke tahun menunjukkan penurunan. Hasil Survei Demografi dan Kesehatan Indonesia (SDKI) tahun 2017 menunjukkan AKN sebesar 15 per 1.000 kelahiran hidup, AKB 24 per 1.000 kelahiran hidup, dan AKABA 32 per 1.000 kelahiran hidup. ${ }^{1,3-5}$

Salah satu upaya untuk menurunkan angka kematian ibu dan anak adalah dengan memperbaiki pelayanan kesehatan terutama kesehatan Ibu dan Anak (KIA). Salah satu bagian dari pelayanan kesehatan ibu dan anak adalah pemanfaatan penggunaan buku KIA. Menurut Keputusan Menteri Kesehatan RI No. 284/MENKES/SK/III/2004 buku KIA merupakan alat untuk mendeteksi secara dini adanya gangguan atau masalah kesehatan ibu dan anak, alat komunikasi dan penyuluhan dengan informasi yang penting bagi ibu, keluarga dan masyarakat mengenai pelayanan, kesehatan ibu dan anak termasuk rujukannya dan paket (standar) pelayanan KIA, gizi, imunisasi, dan tumbuh kembang balita. 6,7

Berdasarkan data RISKESDAS tahun 2018 tentang kepemilikan buku KIA di Indonesia masih ada $24,9 \%$ ibu hamil yang tidak memiliki buku KIA. Sementara untuk ibu yang memiliki anak balita masih ada $34,1 \%$ yang tidak memiliki buku KIA. ${ }^{8}$ Tingkat pengetahuan tentang buku KIA di Bali berkisar 10-30\%. Tentang pemahaman seluruh informasi di dalam buku kia SEBESAR $67,5 \%{ }^{8}$

Penelitian ini bertujuan untuk menentukan tingkat kepemilikan buku KIA dan tingkat pemahaman ibu terhadap buku KIA yang dimiliki.

\section{METODE}

Penelitian ini sebagian dari penelitian dengan menggunakan metode Kuasi eksperimental Pre-Post dimana pada 3 kecamatan di Kabupaten Padang Pariaman. Kecamatan yang diambil adalah kecamatan yang masalah pada anak stunting cukup tinggi dan tingkat kepemilikan buku KIA yang rendah serta angka penimbangan yang rendah. Jumlah sampel yang diperoleh sebanyak 108 
responden dan sebanyak 6 responden di eksklusi karena pindah tempat tinggal sehingga total responden yang dianalisis sebanyak 102 responden ibu hamil dan ibu yang memiliki anak balita.

Data dikumpulkan melalui kuesioner yang sudah disiapkan terhadap 102 responden ibu hamil dan ibu balita. Tenaga pengumpul data dari lulusan DIII Gizi sebanyak 6 orang, mereka dilatih sebelum mengumpulkan data. Kuesioner yang telah selesai di cek dan editing, coding, dan entri. Analisis data dilakukan dengan pendekatan analisis deskriptif.

\section{HASIL DAN PEMBAHASAN}

Berdasarkan tabel 1, lebih dari separuh $(62,7 \%)$ ibu yang memiliki tingkat pendidikan yang tinggi, $81,4 \%$ ibu tidak bekerja atau menjadi ibu rumah tangga.

Tabel 1. Karakteristik Responden

\begin{tabular}{lcc}
\hline \multicolumn{1}{c}{ Variabel } & f & $\%$ \\
\hline $\begin{array}{l}\text { Karakteristik ibu } \\
\text { Umur responden (tahun), } \\
\text { (mean } \pm \text { SD) }\end{array}$ & $30,47 \pm 5,493$ \\
$\begin{array}{l}\text { Pendidikan ibu, f(\%) } \\
\quad \text { Rendah }\end{array}$ & 38 & 37,3 \\
$\quad$ Tinggi & 64 & 62,7 \\
Pekerjaan ibu & & \\
$\quad$ Tidak bekerja/rumah & 83 & 81,4 \\
$\quad$ tangga & & \\
$\quad$ Bekerja & 19 & 18,6 \\
Penghasilan per bulan & $338.725 \pm$ \\
(Rp), (mean $\pm S D)$ & 894.369 \\
Agama & & \\
$\quad$ Islam & 102 & 100 \\
Suku & & \\
$\quad$ Minang & 98 & 96,1 \\
$\quad$ Jawa & 1 & 1 \\
$\quad$ Batak & 1 & 1 \\
$\quad$ Lainnya & 2 & 2 \\
\hline
\end{tabular}

Berdasarkan tabel 2, lebih dari separuh $(56,9 \%)$ suami yang memiliki tingkat pendidikan yang tinggi. Umumnya suami bekerja.

Tabel 2. Karakteristik Suami

\begin{tabular}{lcc}
\hline \multicolumn{1}{c}{ Variabel } & $\mathbf{f}$ & $\%$ \\
\hline Karakteristik suami & & \\
Umur responden (tahun), & $37,76 \pm 37,93$ \\
(mean \pm SD) & & \\
Pendidikan kepala keluarga, & $\mathrm{f}(\%)$ & \\
$\quad$ Rendah & 44 & 43,1 \\
$\quad$ Tinggi & 58 & 56,9 \\
Pekerjaan kepala keluarga & & \\
$\quad$ Tidak bekerja & 0 & 0 \\
$\quad$ Bekerja & 102 & 100 \\
Penghasilan per bulan (Rp), & $3.742 .772 \pm$ \\
(mean \pm SD) & 5.181 .196 \\
Agama & & \\
$\quad$ Islam & 102 & 100 \\
Suku & & \\
$\quad$ Minang & 98 & 96,1 \\
Jawa & 2 & 2 \\
$\quad$ Batak & 1 & 1 \\
$\quad$ Lainnya & 1 & 1 \\
\hline
\end{tabular}

Berdasarkan kepemilikan buku KIA 83,3\% ibu yang memiliki buku KIA dan masih ada ibu yang belum memiliki buku KIA 12,7\%.

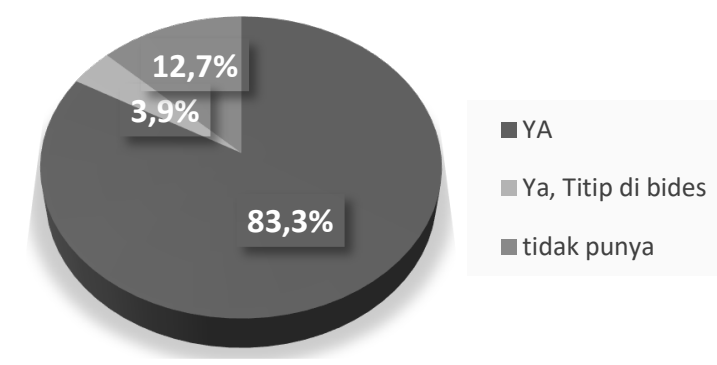

Gambar 1. Persentase kepemilikan buku KIA

Berdasarkan tabel 3, sebagian besar ibu yang tidak mengetahui informasi yang terdapat di dalam buku KIA. 
Tabel 3. Informasi yang diketahui ibu dalam buku KIA

\begin{tabular}{|c|c|c|}
\hline Variabel & $\mathbf{f}$ & $\%$ \\
\hline \multicolumn{3}{|c|}{ Pemeriksaan kehamilan secara rutin } \\
\hline Ada & 12 & 11,8 \\
\hline Tidak & 90 & 88,2 \\
\hline \multicolumn{3}{|l|}{ Imunisasi ibu hamil } \\
\hline Ada & 10 & 9,1 \\
\hline Tidak & 92 & 90,1 \\
\hline \multicolumn{3}{|c|}{ Informasi persiapan melahirkan } \\
\hline Ada & 17 & 16,7 \\
\hline Tidak & 85 & 83,3 \\
\hline \multicolumn{3}{|l|}{ Perawatan ibu hamil } \\
\hline Ada & 19 & 18,6 \\
\hline Tidak & 83 & 81,4 \\
\hline \multicolumn{3}{|c|}{ Tanda bahaya kehamilan } \\
\hline Ada & 28 & 27,5 \\
\hline Tidak & 74 & 72,5 \\
\hline \multicolumn{3}{|l|}{ Tanda melahirkan } \\
\hline Ada & 17 & 16,7 \\
\hline Tidak & 85 & 83,3 \\
\hline \multicolumn{3}{|c|}{ Proses melahirkan (persalinan) } \\
\hline Ada & 17 & 16,7 \\
\hline Tidak & 85 & 83,3 \\
\hline \multicolumn{3}{|c|}{ Tanda bahaya pada proses melahirkan } \\
\hline Ada & 11 & 10,8 \\
\hline Tidak & 91 & 89,2 \\
\hline \multicolumn{3}{|c|}{ Cara menyusui (IMD \& ASI ekslusif) } \\
\hline Ada & 25 & 24,5 \\
\hline Tidak & 77 & 75,5 \\
\hline \multicolumn{3}{|c|}{ Tanda bahaya pada ibu nifas } \\
\hline Ada & 10 & 9,8 \\
\hline Tidak & 92 & 90,2 \\
\hline \multicolumn{3}{|c|}{ Catatan kesehatan ibu hamil dan ibu nifas } \\
\hline Ada & 12 & 11,8 \\
\hline Tidak & 90 & 88,2 \\
\hline \multicolumn{3}{|c|}{ Tanda bayi/anak sehat } \\
\hline Ada & 26 & 25,5 \\
\hline Tidak & 76 & 74,5 \\
\hline \multicolumn{3}{|c|}{ Catatan imunisasi anak } \\
\hline Ada & 18 & 17,6 \\
\hline Tidak & 84 & 82,4 \\
\hline \multicolumn{3}{|l|}{ KMS } \\
\hline Ada & 23 & 22,5 \\
\hline Tidak & 79 & 77,5 \\
\hline
\end{tabular}

Hasil penelitian menunjukkan tingkat pendidikan ibu-ibu yang memiliki buku KIA cukup tinggi. Tingkat pendidikan dan pengetahuan sangat berpengaruh terhadap perubahan sikap dan perilaku. ${ }^{9}$ Semakin tinggi tingkat pendidikan, sikap dan kepercayaan ibu hamil maka semakin mudah menerima informasi dan semakin tinggi pula kesadaran ibu dalam berperilaku menggunakan dan memanfaatkan buku KIA. ${ }^{8,10}$

Tingkat kepemilikan buku KIA 83,3\% cukup tinggi dibandingkan dengan data Riskesdas 2010 sebesar 45,4\% dan Riskesdas 2013 sebesar 52,6\% dan Riskesdas 2018 sebesar $63,9 \%$. Kondisi ini dapat disebabkan oleh tingkat pendidikan ibu, bidan desa terdapat di setiap desa dan bidan ini menetap di desa itu. Di samping itu ibu hamil dipantau terus menerus oleh bidan desa dari posyandu pada setiap bulan. Di daerah ini anak balita diberikan suplementasi biskuit dari Kemenkes yang mesti dipantau pertumbuhan dan perkembangan setiap bulan. ${ }^{1,11}$

Walaupun tingkat kepemilikan buku KIA tinggi di wilayah penelitian, namun sebagian besar responden (>75\%) tidak tahu informasi penting tentang kehamilan, melahirkan, tanda bahaya ibu melahirkan dan nifas, penimbangan anak. Kondisi ini hampir sama dengan penelitian Damayanti 2014 di Denpasar. . $^{812-14}$

Sebaliknya, penelitian Subiyatun (2017) di kota Yogyakarta menemukan dimana ibu hamil dan ibu balita hanya rata-rata di bawah $40 \%$ yang tidak baik pengetahuan tentang isi buku KIA. ${ }^{8}$

Kondisi ini menginformasikan bahwa perlunya secara rutin tiap bulan bidan desa 
mencek dan menjelaskan informasi yang perlu dibaca dan dipahami ibu hamil dan ibu balita di dalam buku KIA. ${ }^{15-17}$

Dari hasil ini juga diketahui masih rendahnya pengetahuan ibu-ibu tentang informasi yang ada di dalam buku KIA. Upaya peningkatan informasi yang dapat dilakukan adalah dengan penggunaan buku KIA oleh ibu. Informasi terkait dengan KIA sudah semakin mudah diakses oleh ibu dengan melalui interaksi ibu dengan tenaga kesehatan, media informasi kesehatan lainnya sehingga meningkatkan pemahaman ibu tentang informasi kesehatan ibu dan anak. ${ }^{18-21}$

\section{SIMPULAN}

Dari penelitian ini diketahui lebih dari separuh ibu yang memiliki tingkat pendidikan yang tinggi dan lebih dari separuh suami ibu yang memiliki tingkat pendidikan yang tinggi. Masih ada ibu-ibu yang tidak memiliki buku KIA. Pengetahuan ibu-ibu masih rendah tentang informasi yang ada dalam buku KIA.

\section{DUKUNGAN FINANSIAL}

Penelitian ini merupakan salah satu bagian dari penelitian besar tentang Peningkatan Peranan Buku KIA, Sistem Pendampingan dan Surveilans Berbasis e-PPGBM Bagi Ibu Hamil serta BADUTA untuk menjaga pertumbuhan dan perkembangan optimal selama 1000 HPK di Kabupaten Padang Pariaman Provinsi Sumatera Barat melalui kerja sama antara Direktorat Gizi Masyarakat Kementerian Kesehatan RI dan Fakultas Kesehatan Masyarakat Universitas Andalas pada tahun 2017 dengan nomor kontrak KM.04.01/2/3151/2017 dan 2647/UN.16.12/PP/2017 tanggal 28 bulan Agustus tahun 2017.

\section{DAFTAR PUSTAKA}

1. Budijanto D. Profil kesehatan Indonesia. Kemenkes RI; 2017.

2. Sistiarani C, Gamelia E, Hariyadi B. Analis kualitas penggunaan buku kesehatan ibu anak. KEMAS. 2014; 10(1):14-20.

3. Balitbang Kesehatan. Riset Kesehatan Dasar. Kemenkes RI; 2007.

4. Balitbang Kesehatan. Riset Kesehatan Dasar. Kemenkes RI; 2010.

5. Balitbang Kesehatan. Riset Kesehatan Dasar. Kemenkes RI; 2013.

6. Keputusan Menteri Kesehatan RI No. 284/MENKES/SK/III/2004 tentang buku KIA.

7. Balitbang Kesehatan. Riset Kesehatan Dasar. Kemenkes RI; 2018.

8. Subiyatun S. Gambaran Pemanfaatan Buku Kesehatan Ibu dan Anak (KIA) oleh ibu hamil. Jurnal Kebidanan dan Keperawatan. 2017; 13(2):203-209.

9. Yangisawa S, Soyano A, Igoreshi H, et al. Health Police Planning. 2015; 30:184-192.

10. Sistiarani C, Gamelia E, Sari DUP. Fungsi pemanfaatan buku KIA terhadap pengetahuan kesehatan ibu dan anak pada ibu. Jurnal Kesehatan Masyarakat Nasional. 2014; 8 (8): 353 - 358. 
11. Pandori J, Kartasurya MI, Winarni S. Penggunaan buku KIA sebagi media edukasi pada ibu hamil: studi di wilayah kerja puskesmas tlogosari kulon, tahun 2018. JKM UUNDIP. 2018; 6(2): 63-73.

12. Annisa FN. Hubungan minat membaca buku KIA dengan pengetahuan ibu hamil tentang buku KIA. Jurnal Promkes. 2016; 4(2): $188-198$.

13. Hanum R, Safitri ME. Hubungan pengetahuan dan sikap ibu hamil tentang pemanfaatan buku KIA di puskesmas Namu Ukur. JBK. 2018; 1(3):152-160.

14. Nakamura Y. Maternal and child health handbook in Japan. JMAJ. 2010; 53(4):259-265.

15. Baequni and Nakamura Y. Is maternal and child health handbook effective?: meta-analysis of the effects of MCH handbook. Journal of International Health. 2012; 27(2):121-127.

16. Yanagisawa S, Soyano A, Igarashi H, Ura M, Nakamura Y. Effect of maternal and child health handbook on maternal knowledge and behaviour: a community-based controlled trial in rural Cambodia. Health Policy and Planning. 2015; 30: 1184-1192.

17. Takeuchi J, Sakagami Y, Perez RC. The mother and child health handbook in japan as a health promotion tool: an overview of its history, contents, use, benefits, and global influence. Global Pediatric Health. 2016; 3:1-9.

18. Aiga H, Nguyen VD, Nguyen CD, Nguyen TTT, and Nguyen LTP. Knowledge, attitude and practices: assessing maternal and child health care handbook intervention in Vietnam. MBC Public Health. 2016; 16:129.

19. Ainiyah NH. Hubungan pemanfaatan buku kesehatan ibu dan anak (KIA) dengan tingkat pengetahuan dan perilaku kesehatan ibu hamil trimester III di Puskesmas Jagir Surabaya. [Tesis]. Yogyakarta: Universitas 'Aisyiyah Yogyakarta; 2017.

20. Astuti DK. Hubungan karakteristik ibu dan pola asuh gizi dengan kejadian balita stunted di desa hargorejo kulonprogi DIY. [Tesis]. Yogyakarta: Universitas Muhammadiyah; 2016.

21. Larasaty VNA. Analisis faktor risiko perilaku penimbangan balita umur $6-59$ bulan di empat provinsi di Kalimantan tahun 2010. [Skripsi]. Jakarta: Universitas Indonesia; 2012 